\title{
Changes in energy content of lunchtime purchases from fast food restaurants after introduction of calorie labelling: cross sectional customer surveys
}

\author{
Tamara Dumanovsky independent consultant ${ }^{1}$, Christina $Y$ Huang doctoral fellow ${ }^{2}$, Cathy A Nonas \\ director of Physical Activity and Nutrition ${ }^{3}$, Thomas D Matte professor of Urban Public Health \\ Program $^{4}$, Mary T Bassett director of African Health Initiative ${ }^{5}$, Lynn D Silver assistant commissioner ${ }^{3}$ \\ ${ }^{1}$ New York, NY, USA ; ${ }^{2}$ Pardee RAND Graduate School, Santa Monica, CA, USA 90407; ${ }^{3}$ New York City Department of Health and Mental Hygiene, \\ Bureau of Chronic Disease, New York; ${ }^{4}$ City University of New York School of Public Health, New York ; Doris Duke Charitable Foundation, New \\ York
}

\begin{abstract}
Objective To assess the impact of fast food restaurants adding calorie labelling to menu items on the energy content of individual purchases.

Design Cross sectional surveys in spring 2007 and spring 2009 (one year before and nine months after full implementation of regulation requiring chain restaurants' menus to contain details of the energy content of all menu items).
\end{abstract}

Setting 168 randomly selected locations of the top 11 fast food chains in New York City during lunchtime hours.

Participants 7309 adult customers interviewed in 2007 and 8489 in 2009.

Main outcome measures Energy content of individual purchases, based on customers' register receipts and on calorie information provided for all items in menus.

Results For the full sample, mean calories purchased did not change from before to after regulation ( $828 v 846 \mathrm{kcal}, \mathrm{P}=0.22$ ), though a modest decrease was shown in a regression model adjusted for restaurant chain, poverty level for the store location, sex of customers, type of purchase, and inflation adjusted cost ( $847 v 827 \mathrm{kcal}, \mathrm{P}=0.01)$. Three major chains, which accounted for $42 \%$ of customers surveyed, showed significant reductions in mean energy per purchase (McDonald's $829 v 785 \mathrm{kcal}$, $\mathrm{P}=0.02$; Au Bon Pain 555 v 475 kcal, $\mathrm{P}<0.001$; KFC 927 v 868 kcal, $\mathrm{P}<0.01$ ), while mean energy content increased for one chain (Subway $749 v 882 \mathrm{kcal}, \mathrm{P}<0.001)$. In the 2009 survey, 15\% (1288/8489) of customers reported using the calorie information, and these customers purchased 106 fewer kilocalories than customers who did not see or use the calorie information (757 v $863 \mathrm{kcal}, \mathrm{P}<0.001)$.

Conclusion Although no overall decline in calories purchased was observed for the full sample, several major chains saw significant reductions. After regulation, one in six lunchtime customers used the calorie information provided, and these customers made lower calorie choices.

\section{Introduction}

Obesity prevalence in the United States is at an all-time high for both adults and children; the most recent data report that a third of adults and $17 \%$ of children and teenagers are obese. ${ }^{12}$ In an effort to refocus the fight against obesity, elected officials and public health professionals are shifting towards legislative policies that alter the food environment to facilitate healthier nutritional choices. ${ }^{3}$ Among such initiatives are soda taxes, restrictions on food marketing to children, updating nutrition guidelines for schools and public procurement, regulation of vending machines, and moratoria on licensing fast food establishments. ${ }^{4-6}$ Requiring chain restaurants to print the energy content of their meals is one such intervention. Since New York City's regulation was passed in 2006, which required chain restaurants to include the calorific value for all items on menus and menu boards, other US jurisdictions have introduced similar policies. $^{7}$ The Patient Protection and Affordable Care Act, approved in March 2010, will require calorie labelling at chain restaurants nationwide. In the United Kingdom, 28 organisations have pledged to implement similar labelling in 2011 as part of the Department of Health's voluntary Responsibility Deal programme. ${ }^{8}$ These include some food chains that have been required to provide calorie labels in New York City.

Several studies support an association between fast food consumption and excessive energy intake. ${ }^{9-12}$ Studies also show that customers often underestimate the number of calories in restaurant meals. ${ }^{13-15}$ Before 2007, nutrition information was seldom available at the point of purchase. Even when the information was available in the store, few customers saw it. ${ }^{16-18}$ Requiring calorie information to appear on menus and menu boards can potentially affect energy intake by increasing consumer awareness of the high energy content of many menu 
items, informing consumer decision making, and by encouraging chains to offer and promote lower calorie options.

Because this was an innovative policy when it was introduced, only limited data on the effectiveness of calorie labelling were available before its approval. Earlier studies were generally conducted in experimental settings where participants were asked to make a meal selection from a predefined menu. A recent review of these studies showed mixed results. ${ }^{19}$ More recent studies using similar designs also have divergent results. While one study found that participants who saw posted calorie information ordered fewer calories, ${ }^{20}$ a second found no significant differences in calories ordered between intervention and control groups. ${ }^{21} \mathrm{~A}$ third study found an effect on parents' food choices for young children but no effect on the adults' choices. $^{22}$

Other studies used customer receipts or sales data to track changes in calories purchased. Elbel and colleagues used customer receipts combined with surveys to compare purchasing patterns one month before and two months after the full enforcement of the New York City regulation in a limited number of fast food stores in four low income neighbourhoods and found no measurable effect on calories purchased. ${ }^{23} \mathrm{~A}$ second study combining sales data with customer surveys at full service restaurants found that customers who used calorie information ordered 75 fewer kilocalories, on average, than before. ${ }^{24} \mathrm{~A}$ third study, which used sales data for more than 100 million transactions at Starbucks, found a 6\% decrease in calories per purchase in New York City after the calorie posting regulation went into effect and no loss of revenue..$^{25}$ A more recent study of the implementation of a similar menu labelling law in Washington State looked at purchases in one Mexican food restaurant chain only and did not find a change in mean calories purchased. ${ }^{26}$ While these studies begin to assess the potential impact of calorie labelling on calories purchased, there is limited research on the effects of repeated exposure to such labelling at a population level or longer term impacts on consumer purchasing patterns.

The New York City Board of Health first approved a calorie labelling regulation in December 2006. In January 2008, after a lawsuit had successfully challenged the initial regulation, the city approved a second health code regulation requiring chain restaurants with 15 or more stores nationwide to provide calorie information prominently on all menus, menu boards, and item tags. ${ }^{27}$ Calorie information was required for all items with a name and a price, and had to be adjacent to and at least as prominent as item name or price. This regulation became effective in March 2008, and full enforcement with fines began in late July 2008.

This paper reports on changes in lunchtime purchases at fast food chains in New York City since the implementation of the city's calorie labelling regulation. Specifically, this study focuses on two outcomes: change in mean energy (kcal) purchased by all customers for each food chain (the hypothesised impact was a 5\% reduction in mean kilocalories per purchase), and difference in mean energy per purchase by self reported awareness and use of calorie information (the hypothesised difference was $10 \%$ ).

\section{Methods}

\section{Sample}

The sampling frame consisted of all 1625 licensed store locations from the 13 chains that together accounted for almost $90 \%$ of the locations covered by the 2006 regulation (some smaller chains were excluded). From this list, we randomly selected 300 locations. Sites that had closed or were located in shopping malls or airports were excluded, resulting in a total of 275 locations in the 2007 sample. The same locations were revisited in spring 2009. At follow-up, 22 locations had closed or did not allow data collection, and these were replaced with restaurants of the same chain in the same or adjacent zip code. Anticipating that customer volume would vary greatly across neighbourhoods, we set targets for data collection at 55 customers or 2 hours for each location. Because published data needed to inform sample size calculations were limited at the time, we estimated the likely mean value and variation in kilocalories per purchase from a study of adolescents. ${ }^{28}$ Assuming a coefficient of variation in kilocalories purchased of $38 \%$ and conservatively assuming a design effect of 4 , we would require a sample of 3600 for each survey to have $80 \%$ power to detect a $5 \%$ reduction in mean energy (kcal) from before to after regulation. To allow for stratified analyses and ensure sufficient sample sizes by fast food chain, we set the target at 10000 for each survey.

Of the 13 chains in the study sample, two were coffee chains with 109 locations. Data for these two coffee chains were excluded from this analysis because purchasing patterns were so different at these chains, with over $60 \%$ of purchases limited to a single drink. Results presented here focus on lunchtime calorie intake for 11 fast food chains with 168 locations.

\section{Data collection}

Data collection was conducted for nine weeks in spring 2007 and spring 2009, from late March through early June. Three-person data collection teams were stationed in front of the sampled locations during weekdays, for $12-2$ pm at fast food chains and 2-4 pm at the two coffee chains. Adult customers were approached as they entered the restaurant and asked to provide their register receipts when exiting and to complete a brief survey; a $\$ 2$ Metrocard (a public transport pass) was offered as an incentive. In addition to collecting their receipts, the teams asked customers to confirm that the purchase was for themselves only and to describe their purchase, including any customisations they requested. All were asked if they saw calorie information in the restaurant and, if so, whether the information affected their purchase. The teams recorded each customer's sex based on observation. In 2009, customers were also asked their age and residential zip code. Surveys were conducted in English only. The institutional review board of the city's health department determined that the study did not require ethical approval as it was an evaluation of a public health intervention.

\section{Data entry}

Each item purchased was entered as it appeared on the customer's receipt. Additional information obtained through the customer survey was also entered (that is, extra items, condiments, order modifications, and diet (low calorie) $v$ non-diet beverage). We used the calorie information posted on the websites of each restaurant chain at 1 March 2007 and 1 March 2009 to ascribe a value to each item, including extras or customisations (such as extra cheese, sauce, or salad dressing). If the customer did not provide details about added items (for example, not specifying the type of salad dressing or dipping sauce), we assigned the lowest caloric value within that category. Data were aggregated by customer to calculate total kilocalories per purchase. 


\section{Measures and statistical analyses}

The two outcomes of interest were: (1) change in mean energy content (kcal) per purchase before and after regulation, and (2) mean energy content $(\mathrm{kcal})$ purchased among customers who said that they used the calorie information when deciding what to order. The second outcome is limited to the period after regulation, when all food chains labelled menu items with calorie information. All analyses adjusted for the clustered sample design, a first stage random sample of stores and second stage of customers within stores. Two tailed $t$ tests with $\alpha<0.05$ were used to test for differences in mean energy before and after regulation and between customers who used calorie information and those who did not.

We used two linear regression models to estimate change in calories per customer from before to after regulation. The first (model 1) controlled for restaurant chain, sex, and neighbourhood poverty. Model 2 further controlled for the number of food items purchased, beverage purchased, and cost. Because food and beverage items purchased and cost can potentially be either confounders-for example, through secular trends or mechanisms of action through which calorie labelling affects purchases - we analysed the data with and without these adjustments. Two similar linear regression models were used to estimate differences in mean calories after regulation (2009 only) between customers who reported using calorie information and those who did not. In addition to the variables mentioned above, these models also include customer age and neighbourhood of residence (data collected in 2009 only). Neighbourhood poverty values for store location and customer's residential zip codes were calculated as the percentage of households in the zip code that were below $200 \%$ of the national poverty level, based on US census data for 2000. The 2007 purchase costs were adjusted for inflation to 2009 costs. ${ }^{29}$ Cases with missing data for any of these variables were excluded from the regression models. SPSS 18.0 (SPSS, Chicago, IL) was used for all analyses.

\section{Results}

Register receipts and surveys were collected from a total of 7750 customers in spring 2007 and from 8730 customers in spring 2009 at 168 fast food chain locations during lunchtime hours (at the two coffee chains, 4038 receipts and surveys were collected in 2007 and 3981 in 2009). Data were excluded if the purchase was for more than one person, if the customer's order could not be identified, or if calorie information for any menu item could not be determined. The final study sample for the 11 lunchtime chains included 7309 customers for 2007 and 8489 for 2009 . Overall, more than $80 \%$ of all customers were approached; the response rate for these customers was $60 \%$. In 2007 only the Subway sandwich chain provided calorie information for a small number of items, for which they made health claims. In 2009, all chains included in this study were largely in compliance with the new regulation. Non-compliance was limited to variations in font sizes or background colours; in some cases, chains did not clearly post calorie information on in-store promotional materials.

Table 1 presents the sample distribution for 2007 and 2009 by fast food chain, customer demographics, and descriptive statistics for the purchases. This table also shows the percentage of customers who reported using the calorie information. McDonald's and Subway each account for a quarter of all restaurants in the study and together account for $58 \%$ of all receipts collected. Conversely, the three pizza chains together account for $12 \%$ of the restaurants included, while their customers account for only $4 \%$ of receipts collected. The sample distributions by fast food chain were similar for the two time periods. In both periods women made up about half of the sample, and a third of receipts came from stores in high poverty neighbourhoods. Purchasing patterns were similar in the two time periods; however, slightly fewer customers purchased a beverage in 2009 ( $54 \%$, compared with $58 \%$ in $2007, \mathrm{P}<0.001$ ). The average cost across all purchases, adjusted for inflation, increased by 42 cents.

Overall, $15 \%$ of customers reported using the calorie information when deciding on their purchase for that day. This was higher at the two sandwich chains, Subway and Au Bon Pain, where over $20 \%$ of customers reported using the posted calorie information (table 1). Women were more likely to report using calorie information ( $18 \% v 13 \%$ of men, $\mathrm{P}<0.001)$, as were customers in stores in the wealthiest neighbourhoods $(19 \% \mathrm{v}$ $17 \%$ in neighbourhoods with moderate poverty and $12 \%$ in stores in the poorest neighbourhoods; $\mathrm{p}<0.001$ ). This pattern was similar by neighbourhood of residence. The youngest customers (18-24 year olds) were the least likely to report using calorie information ( $11 \% v 16 \%$ of older customers, $\mathrm{P}<0.001)$. Customers who reported using calorie information also purchased fewer food items on average $(1.77 v 2.03, \mathrm{P}<0.001)$, and fewer purchased a beverage $(51 \% \vee 54 \%, \mathrm{P}=0.03)$. There was no difference in purchase price between customers who reported using calorie information and those who did not $(\$ 5.19$ $v \$ 5.07, \mathrm{P}=0.07$ ).

At lunch locations, unadjusted pre-regulation mean energy content per purchase ranged from a low of $555 \mathrm{kcal}$ at Au Bon Pain to a high of $1309 \mathrm{kcal}$ at Pizza Hut. At hamburger chains, the means were within $100 \mathrm{kcal}$ across the three chains, with a low of 829 at McDonald's and a high of 924 at Burger King. Mean energy at the two chicken fast food chains were similar (927 kcal at KFC and 949 at Popeye's), while mean energy content per purchase across the three pizza chains was more varied. The post-regulation data show similar trends between chains (table 2).

After regulation, three major chains with large sample sizes showed statistically significant reductions in mean energy content per purchase: a $44 \mathrm{kcal}$ reduction at McDonald's (829 $v 786, \mathrm{P}<0.02), 80 \mathrm{kcal}$ reduction at Au Bon Pain (555 v 475, $\mathrm{P}<0.001)$, and $59 \mathrm{kcal}$ reduction at $\mathrm{KFC}(927 v 868, \mathrm{P}<0.001)$. Together, these three chains represent $42 \%$ of all customers in our study. One chain, Subway, showed a significant increase in mean energy content per purchase (749v882 kcal, $\mathrm{P}<0.001)$. Overall, combining unadjusted data from the 11 fast food chains, there was no significant change in mean calories per purchase from before to after regulation ( $828 v 846 \mathrm{kcal}, \mathrm{P}=0.22)$ (table 2).

Customers who reported using the calorie information after regulation purchased 106 fewer calories, on average, compared with customers who didn't see or didn't use the information. This difference was highest at hamburger chains, where customers who reported using calorie information reduced the mean energy content of their purchases by $>130 \mathrm{kcal}$ compared with other customers. The reduction was significant at six chains and overall $(\mathrm{P}<0.001)$. This pattern held for both men and women, for all age groups, and across neighbourhoods (table 3).

\section{Regression models}

In order to control for some of this variability between chains and changes in the composition of the sample from 2007 to 2009, we used linear regression models to estimate kilocalories 
per purchase. Table 1 provides the descriptive statistics for the variables included in these multivariate models, and tables 4 and 5 present the results of the regression analyses.

\section{Difference in mean energy content of purchase before and after regulation}

Model 1 estimates change in mean energy for all purchases from before to after regulation, adjusting for restaurant chain, poverty level for the store location, and sex of customers (table 4). The results of this model are similar to the crude estimates in table 2 , with a non-significant $15 \mathrm{kcal}$ increase after regulation. Model 2-which adds adjustments for the type of purchase, including number of food items, whether a beverage was purchased, and inflation adjusted cost-produces a decrease of $20 \mathrm{kcal}$ in mean energy content per lunchtime purchase, from $847 \mathrm{kcal}$ in 2007 to $827 \mathrm{kcal}$ in $2009(\mathrm{P}=0.01)$ (table 4).

\section{Difference in mean energy content of purchase by use of calorie information}

The two models presented in table 5 compare energy content per purchase between customers who reported using the calorie information in 2009 with all other customers in 2009. After adjustment for restaurant chain, neighbourhood poverty, age, and sex, the customers who reported using calorie information purchased an average of 96 fewer kilocalories compared with customers who didn't use the information (model 1). After further adjustment for purchase type, including number of items, beverage purchase, and cost, customers who reported using calorie information purchased 78 fewer kilocalories than those who did not $(782 v 859 \mathrm{kcal}, \mathrm{P}<0.001)$.

\section{Discussion}

\section{Summary of findings and relevant contextual issues}

Overall, there was no change in mean energy content of lunchtime purchases from fast food chains after introduction of calorie information for all menu items. However, this finding was not uniform across all the chains, with some showing significant reductions in mean energy intake, and one showing a significant increase.

Analyses by chain are, of course, limited as some chains had small sample sizes based on the study design. The variability that was evident by chain is probably due to several factors, including changes in customer purchasing patterns and changes in menu options and promotions over the two years of the study. For example, reductions in mean energy per purchase were evident at chains with a broader range of menu items, including McDonald's and Wendy's.

On the industry side, chains that introduced new lower calorie menu items were among those that showed a reduction in mean energy content per purchase. For example, customers of Au Bon Pain, which launched its "Portions" menu in March 2008, reduced their energy content per purchase by $14 \%$, and customers of KFC, which added grilled chicken to its fried chicken menu in April 2009, ${ }^{31}$ reduced their energy content per purchase by $6 \%$. Conversely, the impact of economic incentives on food choices was evidenced by the sharp increase in mean energy per purchase at Subway coinciding with the promotion of a super sized portion-the " $\$ 5$ foot-long"-first introduced nationally in $2008{ }^{32}$ This is somewhat surprising because Subway promotes weight management and was the only chain to provide calorie labelling for some food items in 2007. In 2007, one in four of the Subway customers in the study sample purchased a "foot-long" sandwich, and this had increased to three in four by 2009.

Changes in the mean energy content of purchases from chains with low customer volume in the sample could not be accurately assessed. Despite this variability across chains, the data show a modest $20 \mathrm{kcal}$ decrease for the sample as a whole when sex, neighbourhood poverty, items purchased, and cost are held constant. The unadjusted data did not show a significant change in mean calories purchased; however, there was an increase in mean cost, and fewer diners purchased a beverage. While these changes may be outcomes of calorie labelling, they could also be confounders indicating a change in the customer profile over the two years. Either model is plausible, and both are presented.

Importantly, self reported use of calorie information was associated with lower calorie purchases. One in six customers reported using the calorie information when making their fast food purchase; compared with other customers, these customers purchased an average of 96 fewer kilocalories overall after adjustment for demographics; this translates to $11 \%$ lower energy content for these customers. While these numbers may be small, an $11 \%$ reduction in energy content per meal for one in six fast food purchases could have a substantial public health impact. Further, no negative unintended consequences of calorie labelling were identified.

Although fast food customers in the high poverty neighbourhoods were less likely to report using the calorie information, those who did so in these neighbourhoods showed reductions in kilocalories purchased similar to those in wealthier neighbourhoods, contrary to the findings of Elbel et al. ${ }^{23}$ If the proportion of calorie aware consumers were raised through education, prominent labelling of energy content of groceries, or other public campaigns to complement the regulation, it is possible that the proportion of customers using calorie information effectively might also increase. Likewise, as the new national calorie labelling regulation is implemented, we expect that there will be additional pressures on chain restaurants to offer and promote lower calorie items.

As more people rely on foods prepared outside the home, there is a strong and growing consensus that consumers want to know what they are eating so that they can make informed choices. Requiring that fast food chains supply calorie information provides a valuable resource for those customers who choose to use it. Although public opinion on the measure was not assessed in this study, high levels of support (84\%) have been reported. $^{33}$

On the industry side, there is growing evidence that this regulation may provide an incentive to companies to offer healthier options or reformulate their most popular products. It is worth noting that the industry initially opposed the regulation but eventually reversed its position and supported the legislation that created the new national requirement in the US; some of these companies have pledged to provide the information voluntarily in the United Kingdom. Researchers have speculated that a disclosure regulation could initiate a virtuous cycle, where changes in New York City's fast food restaurants may spur change in other regions or food sectors. ${ }^{34}$ Since the New York City regulation took effect, various news media have reported changes to menus by affected establishments. For example, the sandwich chain Cosi's has switched to using a low fat mayonnaise in its sauces ${ }^{35}$ saving 350 calories on some sandwiches; Starbucks switched from whole milk to $2 \%$ fat milk as its default ${ }^{36}$; and Applebee's has a menu of choices under 550 calories. ${ }^{37}$ More changes in menu offerings may be expected 
as calorie labelling becomes effective nationwide in 2010 and 2011.

\section{Strengths and limitations of the study}

This study is among the first to assess the population level effects of a calorie labelling regulation. By analysing customer purchases for a random sample of the most common fast food chains in New York City, the data represent the average fast food weekday lunchtime purchase.

Despite its advantages, this study has several limitations. First, the data are limited to New York City, and the external validity of the findings is as yet unknown. Furthermore, customers may be eating fast food more or less often; which would not be captured by this study design. Customers who saw and used calorie information may have been differently motivated from those who did not, and certain chains are likely to attract customers who may be more inclined to use calorie information. However, it may be the case that posting calories increases awareness for all customers, and we might expect the percentage of customers who use calorie information to increase over time.

Our objective data represent energy (kcal) purchased, not consumed. We had to rely on customers' reporting as to whether they used the calorie information and whether the food was for themselves alone, and these could be subject to reporting bias. Although it is possible that customers did not consume everything they bought, research suggests that availability is a strong predictor of calories consumed. ${ }^{38} 39$

Because the lunchtime street intercept method limited the amount of data that could be collected, demographic information and data on customers' frequency of fast food consumption were limited, especially in the baseline period. It was therefore not possible to assess differences between those exposed to the information more or less frequently or those belonging to different demographic groups. The use of a lunchtime only sample also precluded analysis of the effects of calorie labelling at other mealtimes.

This analysis does not attempt to distinguish between the multiple potential mechanisms by which calorie labelling could affect the energy content of purchases, such as changes in menu offerings, more informed consumer choice, or differences in pricing or promotion; nor does it seek to isolate the effects on consumer choice alone. Each one of these mechanisms can and should be an object of separate study.

The study design does not include a control group, so secular trends that may have affected the results could not be isolated. Because the adoption of the city's calorie labelling regulation was delayed, the time between the two data collection periods was extended from one to two years, potentially encompassing more variability than anticipated. Intervening factors, including the severe economic downturn, may have affected customer purchasing patterns in 2009, such as by seeking greater perceived value for their money or by increasing or reducing patronage.

\section{Conclusions and policy implications}

Results from this study suggest that there is a positive effect of calorie labelling on energy intake at some major chains, and that use of the information is clearly associated with lower calorie purchases across chains. However, a clear reduction in energy intake across the full sample was not found. A strong research agenda is needed for nutrition interventions. It will be particularly important to assess the energy content of fast food purchases periodically as restaurant chains reformulate menu items or change their menu offerings in response to the national legislation. Systematic tracking of changes to fast food menus would also be useful, in terms of energy, nutrients, and pricing, to examine the industry response to policy requirements. Calorie labelling is only one part of a framework to address the obesity epidemic. Additional strategies are needed to reduce energy intake on a population basis. Special attention should be focused on educating consumers on how to interpret and use nutrition information. Definitive assessments of the full impact and effectiveness of calorie labelling will require a long term perspective as calorie labelling goes national and expands to other countries and chains have greater incentives to modify their menus.

We thank Joe Egger and Kevin Konty for their review of the data analyses and the members of the Robert Wood Johnson Foundation Menu Labeling Working Group for their continuing collaboration. We also thank all of the data collectors who worked on this project.

Funding: This research was funded by the City of New York and by the Robert Wood Johnson Foundation Healthy Eating Research Program (grant No 65839). All research was conducted independently of the external funder.

Competing interests: All authors have completed the Unified Competing Interest form at www.icmje.org/coi_disclosure.pdf (available on request from the corresponding author) and declare that (1) TD, CYH, CAN, and LDS had outside support for the submitted work through a grant from the Robert Wood Johnson Foundation awarded to the New York City Department of Health and Mental Hygiene; (2) no authors have relationships that might have an interest in the submitted work in the previous 3 years; (3) their spouses, partners, or children have no financial relationships that may be relevant to the submitted work; and (4) no authors have non-financial interests that may be relevant to the submitted work.

Ethical approval: Not required.

Contributors: At the time of this research, all authors were with the New York City Department of Health and Mental Hygiene. TD led the study and is the guarantor for the paper. LDS, MTB, and CAN led the implementation of the calorie labelling policy. MTB, TDM, LDS, and TD had the idea for the research. TD and CYH led the data collection, undertook the analysis, and drafted the article. All authors participated in the interpretation of results, revision, and approval of the final draft. TD and CYH had full access to the data and can take responsibility for the integrity of the data and the accuracy of the data analysis.

Data sharing: No additional data available.

1 Flegal KM, Carroll MD, Ogden CL, Curtin LR. Prevalence and trends in obesity among US adults, 1999-2008. JAMA 2010: published online 13 January.

2 Ogden CL, Carroll MD, Flegal KM. High body mass index for age among US children and adolescents, 2003-2006. JAMA 2008;299:2401-5.

3 Silver LD, MT Bassett. Food safety for the 21st century. JAMA 2008;300:957-9.

4 Brownell KD, Farley T, Willett WC, Popkin BN, Chaloupka FJ, Thompson JW, et al. The public health and economic benefits of taxing sugar-sweetened beverages. N Engl J Med 2009:361:1599-605.

5 Harris JL, Pomeranz JL, Lobstein T, Brownell KD. A crisis in the marketplace: how food marketing contributes to childhood obesity and what can be done. Ann Rev Public Health 2009;30:211-25.

6 Sallis JF, Glanz K. Physical activity and food environments: solutions to the obesity epidemic. Milbank Q 2009;87:123-54.

7 Center for Science in the Public Interest. http://cspinet.org/new/pdf/ml_map.pdf.

8 United Kingdom Department of Health. Public health responsibility deal. 2011. http:// responsibilitydeal.dh.gov.uk/f1-calorie-labelling.

9 Rosenheck R. Fast food consumption and increased caloric intake: a systematic review of a trajectory towards weight gain and obesity risk. Obes Rev 2008;9:535-47.

10 Pereira MA, Kartashov Al, Ebbeling CB, Van Holm M, Slattery ML, Jacobs DR Jr, et al. Fast-food habits, weight gain, and insulin resistance (the CARDIA study): 15-year Fast-food habits, weight gain, and insulin resistance (the CARDIA study): 15-yea
prospective analysis. Lancet 2005;365:36-42. [Erratum. Lancet 2005;365:1030.]

prospective analysis. Lancet 2005;365:36-42. [Erratum. Lancet 2005;365:1030.]
1 Bowman SA, Vinyard BT. Fast food consumption of US adults: impact on energy and nutrient intakes and overweight status. J Am Coll Nutr 2004;23:163-8.

12 Harnack L, French S. Fattening up on fast food. J Am Diet Assoc 2003;103:1296-7.

13 Burton S, Creyer EH, Kees J, Huggins K. Attacking the obesity epidemic: the potential health benefits of providing nutrition information in restaurants. Am J Public Health 2006:96:1669-75. 


\section{What is already known on this topic}

In January 2008 New York City fully implemented a regulation requiring chain restaurants to provide calorie information prominently for all items on menus and menu boards

Limited data are available on the effectiveness of calorie labelling to reduce the energy content of purchased meals, and the results are conflicting

\section{What this study adds}

Between 2007 (before the regulation) and 2009 (after its implementation) the energy content of lunchtime purchases in New York City declined significantly at three major fast food chains, but not across the entire sample, and it increased at one chain when large portions were heavily promoted

After regulation, one in six lunchtime customers used the calorie information provided, and these customers made lower energy choices

14 Wansick B, Chandon P. Meal size, not body size, explains errors in estimating calorie content of meals. Ann Intern Med 2006;145:326-32.

15 Backstrand J, Wootan MG, Young LR, Hurley J. Fat chance. Center for Science in the Public Interest, 1997.

16 Dumanovsky T, Huang CY, Bassett MT, Silver LD. Consumer awareness of fast-food calorie information in New York City after implementation of a menu labeling regulation. Am J Public Health 2010;100:2520-5.

17 Roberto CA, Agnew H, Brownell KD. An observational study of consumers' accessing of nutrition information in chain restaurants. Am J Public Health 2009:99:820-1.

18 Bassett MT, Dumanovsky T, Huang C, Silver LD, Young C, Nonas C, et al. Purchasing behavior and calorie information at fast-food chains-New York City, 2007. Am J Public Health 2008;98:1457-9.

19 Larson N, Story M. Menu labeling: does providing nutrition information at the point of purchase affect consumer behavior? A research synthesis. Healthy Eating Research national program. Robert Wood Johnson Foundation, 2009

20 Roberto CA, Larsen PD, Agnew H, Baik J, Brownell KD. Evaluating the impact of menu labeling on food choices and intake. Am J Public Health 2010;100:312-8.

21 Harnack L, French S, Oakes J, Story MT, Jeffery RW, Rydell SA. Effects of calorie labeling and value size pricing on fast food meal choices: from an experimental trial. Int $J$ Behav Nutr Phys Act 2008;5:63

22 Tandon PS, Wright J, Zhou C, Rogers CB, Christakis DA. Nutrition menu labeling may lead to lower-calorie restaurant meal choices for children. Pediatrics 2010;125:244-8.

23 Elbel B, Kersh R, Brescoll VL, Dixon LB. Calorie labeling and food choices: a first look at the effects on low-income people in New York City. Health Affairs 2009;28:w1110-21.

24 Pulos E, Leng K. Evaluation of a voluntary menu-labeling program in full-service restaurants. AJPH 2010;100:1035-9.

25 Bollinger B, Leslie P, Sorenson A. Calorie posting in chain restuarants. The National Bureau of Economic Research, working paper no 15648. 2010. www.nber.org/papers/ w15648.

26 Finkelstein EA, Kiersten L, Strombotne BA, Chan N, Krieger J. Mandatory menu labeling in one fast-food chain in King County, Washington. Am J Prev Med 2011;40:122-7.
27 Farley TA, Caffarelli A, Bassett MT, Silver L, Frieden TR. New York City's fight over calorie labeling. Health Affairs 2009;28:w1098-109.

28 Yamamoto JA, Yamamoto JB, Yamamoto BE, Yamamoto LG. Adolescent fast food and restaurant ordering behavior with and without calorie and fat content menu information. $J$ Adolesc Health 2005;37:397-402.

29 US Department of Labor, Bureau of Labor Statistics. CPI inflation calculator. 2011. www. bls.gov/data/inflation calculator.htm.

30 Au Bon Pain launches "Portion" line. Quick Service Restaurant Magazine, 11 March 2008.

31 KFC's new secret? Grilled chicken. Quick Service Restaurant Magazine, 14 April 2009.

32 Hartford J. The $\$ 5$ phenomenon. Quick Service Restaurant Magazine, web exclusive. 2011. www.qsrmagazine.com/articles/exclusives/0908/five_dollars-1.phtml.

33 Berman M, Lavizzo-Mourey R. Obesity prevention in the information age: caloric information at the point of purchase. JAMA 2008;300:433-5.

34 Quinnipiac University Polling Institute. New Yorkers big on sugar drink tax, calorie counts. 2011. www.quinnipiac.edu/ $\times 1302 . x m l$ ?Release $I D=1425$

35 Cosi launches Lighten Up! menu. Quick Service Restaurant Magazine, 9 September 2008.

36 Starbucks goes low fat. Quick Service Restaurant Magazine, 31 May 2007.

37 Jargon J. Restaurants begin to count calories. Wall Street Journal, 22 January 2010. http://online.wsj.com/article/SB10001424052748704381604575005530811257728.htm

38 Wansink $B$, van Ittersum K. Portion size me: downsizing our consumption norms. J Am Diet Assoc 2007;107:1103-6

39 Diliberti N, Bordi PL, Conklin MT, Roe LS, Rolls BJ. Increased portion size leads to increased energy intake in a restaurant meal. Obes Res 2004;12:562-8.

Accepted: 6 June 2011

Cite this as: BMJ 2011;343:d4464 


\section{Tables}

Table 1| Details of lunchtime purchases from fast food outlets in New York City: stores and customers in samples for 2007 and 2009 and customers seeing and using calorie information in 2009. Values are numbers (percentages) unless stated otherwise

\begin{tabular}{|c|c|c|c|c|c|c|c|c|}
\hline & \multirow{2}{*}{$\begin{array}{c}\text { No of } \\
\text { stores } \\
(n=168)\end{array}$} & \multicolumn{3}{|c|}{ All receipts } & \multicolumn{4}{|c|}{ Use of calorie information, 2009} \\
\hline & & $2007(n=7311)$ & $2009(n=8489)$ & $\begin{array}{l}P \text { value of } \\
\text { difference }\end{array}$ & No $(n=7073)^{\star}$ & Yes $(n=1288)^{*}$ & $\begin{array}{l}P \text { value of } \\
\text { difference }\end{array}$ & $\begin{array}{c}\text { Yes as proportion } \\
\text { of total }\end{array}$ \\
\hline Outlet: & & & & & & & & $1288 / 8489(15.2)$ \\
\hline McDonald's & $45(27)$ & $2454(33.6)$ & $2815(33.2)$ & \multirow[t]{11}{*}{0.001} & $2353(33.3)$ & $417(32.4)$ & \multirow[t]{11}{*}{$<0.001$} & $417 / 2815(14.8)$ \\
\hline Burger King & $22(13)$ & $1075(14.7)$ & $1223(14.4)$ & & $1077(15.2)$ & $135(10.5)$ & & $135 / 1223(11.0)$ \\
\hline Wendy's & $11(7)$ & $434(5.9)$ & $567(6.7)$ & & $481(6.8)$ & $79(6.1)$ & & 79/567 (13.9) \\
\hline Subway & $47(28)$ & $1830(25.0)$ & $2047(24.1)$ & & $1545(21.8)$ & $471(36.6)$ & & $471 / 2047(23.0)$ \\
\hline Au Bon Pain & $2(1)$ & $159(2.2)$ & $150(1.8)$ & & $118(1.7)$ & $31(2.4)$ & & $31 / 150(20.7)$ \\
\hline $\mathrm{KFC}$ & $11(7)$ & $421(5.8)$ & $569(6.7)$ & & $493(7.0)$ & $66(5.1)$ & & $66 / 569(11.6)$ \\
\hline Popeye's & $5(3)$ & $357(4.9)$ & $465(5.5)$ & & $414(5.9)$ & $40(3.1)$ & & 40/465 (8.6) \\
\hline Domino's & $10(6)$ & $44(0.6)$ & $55(0.6)$ & & $52(0.7)$ & $1(0.1)$ & & $1 / 55(1.8)$ \\
\hline Pizza Hut & $6(4)$ & $81(1.1)$ & $58(0.7)$ & & $49(0.7)$ & $7(0.5)$ & & $7 / 58(12.1)$ \\
\hline Papa John's & $5(3)$ & $206(2.8)$ & $202(2.4)$ & & $193(2.7)$ & $7(0.5)$ & & 7/202 (3.5) \\
\hline Taco Bell & $4(2)$ & $250(3.4)$ & $338(4.0)$ & & $298(4.2)$ & $34(2.6)$ & & $34 / 338(10.1)$ \\
\hline \multicolumn{9}{|l|}{ Sex: } \\
\hline Men & - & $3473(47.5)$ & $4177(49.2)$ & \multirow[t]{2}{*}{0.047} & $3586(50.7)$ & $538(41.8)$ & \multirow[t]{2}{*}{$<0.001$} & $538 / 4177(12.9)$ \\
\hline Women & - & $3714(50.8)$ & $4194(49.4)$ & & 3409 (48.2) & $732(56.8)$ & & 732/419 (17.5) \\
\hline Missing & - & $124(1.7)$ & $119(1.4)$ & & $85(1.2)$ & $19(1.5)$ & & - \\
\hline \multicolumn{9}{|l|}{ Age (years)t: } \\
\hline $18-24$ & - & - & $1494(17.6)$ & \multirow[t]{5}{*}{-} & $1316(18.6)$ & $158(12.3)$ & \multirow[t]{4}{*}{$<0.001$} & 158/1494 (10.6) \\
\hline $25-34$ & - & - & 2589 (30.5) & & $2143(30.3)$ & $412(32.0)$ & & $412 / 2589(15.9)$ \\
\hline $35-44$ & - & - & $2165(25.5)$ & & $1782(25.2)$ & $345(26.8)$ & & $345 / 2165$ (15.9) \\
\hline$\geq 45$ & - & - & $1800(21.2)$ & & $1768(25.0)$ & 350 (27.2) & & $350 / 1800(19.4)$ \\
\hline Missing & - & - & $450(5.3)$ & & $64(0.9)$ & $22(1.7)$ & & - \\
\hline \multicolumn{9}{|l|}{$\begin{array}{l}\text { Poverty by customer } \\
\text { residence†‡: }\end{array}$} \\
\hline Low & - & - & 1375 (16.2) & & $1103(15.6)$ & 254 (19.7) & \multirow[t]{4}{*}{$<0.001$} & $254 / 1375$ (18.5) \\
\hline Moderate & - & - & 2759 (32.5) & & $2256(31.9)$ & $459(35.6)$ & & 459/2759 (16.6) \\
\hline High & - & - & $3438(40.5)$ & & $2992(42.3)$ & $402(31.2)$ & & 402/3438 (11.7) \\
\hline Outside city & - & - & $849(10.0)$ & & $686(9.7)$ & $162(12.6)$ & & $162 / 849$ (19.1) \\
\hline Missing & - & - & $68(0.8)$ & & $35(0.5)$ & $12(0.9)$ & & - \\
\hline \multicolumn{9}{|l|}{$\begin{array}{l}\text { Poverty by store } \\
\text { location‡: }\end{array}$} \\
\hline Low & - & $1974(27.0)$ & $2521(29.7)$ & \multirow[t]{3}{*}{0.001} & $2023(28.6)$ & $477(37.0)$ & \multirow[t]{3}{*}{$<0.001$} & $477 / 2521$ (18.9) \\
\hline Moderate & - & $2822(38.6)$ & $3183(37.5)$ & & 2645 (37.4) & $489(38.0)$ & & 489/3183 (15.4) \\
\hline High & - & 2508 (34.3) & $2784(32.8)$ & & $2412(34.1)$ & $323(25.1)$ & & $323 / 2784(11.6)$ \\
\hline \multicolumn{9}{|l|}{$\begin{array}{l}\text { Description of } \\
\text { purchase: }\end{array}$} \\
\hline Beverage & - & 4211 (57.6) & 4542 (53.5) & $<0.001$ & $3812(53.9)$ & $653(50.7)$ & 0.03 & - \\
\hline $\begin{array}{l}\text { Mean (SD) No of } \\
\text { food items }\end{array}$ & - & $1.98(1.2)$ & $1.99(1.2)$ & 0.53 & $2.03(1.3)$ & $1.77(1.1)$ & $<0.001$ & - \\
\hline Mean (SD) cost (\$) & - & $4.67(2.1)$ & $5.09(2.4)$ & $<0.001$ & $5.07(2.4)$ & $5.19(2.2)$ & 0.07 & - \\
\hline
\end{tabular}

*Numbers do not add up to 8489 because some customers did not provide the information.

†Age and neighbourhood of residence were not collected in 2007.

$\ddagger$ Poverty is categorised by percentage of households in the store location or customer's residential zip code that were below twice the national poverty level: $<25 \%$ in low poverty neighbourhoods, $25 \%-45 \%$ in moderate poverty neighbourhoods, $>45 \%$ in high poverty neighbourhoods. 
Table 2| Change in mean energy content of lunchtime purchases from fast food outlets between 2007 and 2009, before and after introduction of calorie labelling

\begin{tabular}{|c|c|c|c|}
\hline & \multicolumn{2}{|c|}{ Mean $(95 \% \mathrm{Cl})$ energy content/purchase (kcal)* } & \multirow[b]{2}{*}{ Difference ( $P$ value) } \\
\hline & Spring 2007 & Spring 2009 & \\
\hline Outlet: & $827.8(806.5$ to 849.0$)$ & 846.1 (825.9 to 866.4$)$ & $18.4(0.22)$ \\
\hline McDonald's & $829.2(802.6$ to 855.9$)$ & $785.2(758.9$ to 811.5$)$ & $-44.0(0.02)$ \\
\hline Burger King & $923.8(888.8$ to 958.9$)$ & 967.4 (928.1 to 1006.8$)$ & $43.6(0.10)$ \\
\hline Wendy's & $858.0(807.1$ to 908.8$)$ & 820.9 (771.3 to 870.5$)$ & $-37.1(0.31)$ \\
\hline Subway & $749.2(722.1$ to 776.4$)$ & $882.3(859.8$ to 904.8$)$ & $133.1(<0.001)$ \\
\hline Au Bon Pain & $554.5(513.4$ to 595.6$)$ & 474.5 (455.2 to 493.8$)$ & $-80.0(<0.001)$ \\
\hline KFC & 926.7 (896.1 to 957.3$)$ & 867.8 (841.8 to 893.8$)$ & $-58.9(0.004)$ \\
\hline Popeye's & 948.5 (883.7 to 1013.2$)$ & 974.5 (943.0 to 1006.0$)$ & $26.1(0.48)$ \\
\hline Domino's & 1309.1 (978.8 to 1639.5$)$ & $1028.9(862.4$ to 1195.5$)$ & $-280.2(0.14)$ \\
\hline Pizza Hut & $1039.0(962.9$ to 1115.1$)$ & 942.8 (836.7 to 1048.8$)$ & $-96.2(0.14)$ \\
\hline Papa John's & 622.8 (468.5 to 777.1$)$ & 571.4 (486.9 to 655.8$)$ & $-51.4(0.57)$ \\
\hline Taco Bell & $773.2(670.3$ to 876.1$)$ & 807.7 (764.6 to 850.9$)$ & $34.5(0.54)$ \\
\hline \multicolumn{4}{|l|}{ Sex: } \\
\hline Men & 886.3 (860.8 to 911.8$)$ & 901.0 (879.1 to 922.9$)$ & $14.7(0.39)$ \\
\hline Women & 771.2 (749.7 to 792.8 ) & 792.7 (770.7 to 814.8$)$ & $21.5(0.16)$ \\
\hline \multicolumn{4}{|c|}{ Poverty by store locationt: } \\
\hline Low & 806.1 (762.3 to 849.8$)$ & 829.9 (786.6 to 873.3$)$ & $23.9(0.44)$ \\
\hline Moderate & $832.0(804.0$ to 860.0$)$ & 849.0 (817.2 to 880.7$)$ & $16.9(0.43)$ \\
\hline High & 840.0 (800.7 to 879.3$)$ & 857.6 (827.5 to 887.7$)$ & $17.5(0.48)$ \\
\hline
\end{tabular}

*1 $\mathrm{kcal}=4.184$ kilojoules.

†Poverty is categorised by percentage of households in the store's zip code that were below twice the national poverty level: <25\% in low poverty neighbourhoods, $25 \%-45 \%$ in moderate poverty neighbourhoods, $>45 \%$ in high poverty neighbourhoods. 
Table 3| Difference in mean energy content of lunchtime purchases from fast food outlets in 2009 between customers who reported using information on calorie labelling and those who did not

\begin{tabular}{|c|c|c|c|}
\hline & \multicolumn{2}{|c|}{ Mean $(95 \% \mathrm{Cl})$ energy content/purchase $(\mathrm{kcal})^{\star}$} & \multirow[b]{2}{*}{ Difference ( $P$ value) } \\
\hline & Did not use information & Used information & \\
\hline Outlet: & $863.0(841.6$ to 884.4$)$ & 757.3 (732.0 to 782.5$)$ & $-105.7(<0.001)$ \\
\hline McDonald's & 806.4 (778.3 to 834.5$)$ & 673.4 (634.9 to 711.8 ) & $-133.0(<0.001)$ \\
\hline Burger King & 982.9 (941.3 to 1024.5$)$ & 826.8 (754.7 to 898.9$)$ & $-156.1(0.003)$ \\
\hline Wendy's & 842.9 (788.9 to 897.0$)$ & 703.7 (636.9 to 770.5$)$ & $-139.2(0.002)$ \\
\hline Subway & 904.8 (879.9 to 929.7 ) & 814.2 (785.5 to 842.9 ) & $-90.6(<0.001)$ \\
\hline Au Bon Pain & 480.9 (471.1 to 490.7$)$ & 440.1 (375.2 to 505.1$)$ & $-40.8(0.23)$ \\
\hline KFC & 872.6 (846.9 to 898.2$)$ & 849.3 (782.4 to 916.2$)$ & $-23.3(0.54)$ \\
\hline Popeye's & 980.2 (944.1 to 1016.4$)$ & 878.8 (739.7 to 1017.9$)$ & $-101.4(0.17)$ \\
\hline Domino's & 1038.5 (864.8 to 1212.2 ) & $1000.0(1000.0$ to 1000.0$)$ & $-38.5(-)$ \\
\hline Pizza Hut & 1000.1 (923.2 to 1076.9$)$ & 691.8 (482.4 to 901.2 ) & $-308.3(0.03)$ \\
\hline Papa John's & 576.4 (494.4 to 658.4$)$ & 434.6 (344.4 to 524.9 ) & $-141.8(0.03)$ \\
\hline Taco Bell & 796.7 (742.6 to 850.8$)$ & 886.9 (754.1 to 1019.7$)$ & $90.2(0.29)$ \\
\hline \multicolumn{4}{|l|}{ Sex: } \\
\hline Men & 913.7 (890.1 to 937.4$)$ & 819.2 (788.4 to 849.9 ) & $-94.6(0.003)$ \\
\hline Women & 810.3 (787.1 to 833.6$)$ & 711.3 (681.8 to 740.9 ) & $-99.0(<0.001)$ \\
\hline \multicolumn{4}{|l|}{ Age $\left(\right.$ years) ${ }^{*}$ : } \\
\hline $18-24$ & 886.4 (857.1 to 915.7 ) & 821.6 (763.0 to 880.1$)$ & $-64.8(0.05)$ \\
\hline $25-34$ & 898.0 (875.5 to 920.5$)$ & 784.1 (749.5 to 818.7 ) & $-113.8(<0.001)$ \\
\hline $35-44$ & 884.6 (855.3 to 913.9 ) & 765.5 (724.8 to 806.2 ) & $-119.1(<0.001)$ \\
\hline$\geq 45$ & 779.8 (753.5 to 806.1$)$ & $682.9(640.8$ to 725.0$)$ & $-96.9(<0.001)$ \\
\hline \multicolumn{4}{|c|}{ Poverty by customer residencet: } \\
\hline Low & 844.0 (799.5 to 888.4$)$ & 729.7 (675.3 to 784.1$)$ & $-114.3(0.002)$ \\
\hline Moderate & 868.1 (844.3 to 892.0$)$ & 766.5 (733.5 to 799.6$)$ & $-101.6(<0.001)$ \\
\hline High & 871.1 (844.6 to 897.7 ) & 763.5 (721.6 to 805.3 ) & $-107.7(<0.001)$ \\
\hline Outside city & 837.9 (788.5 to 887.3$)$ & 766.9 (717.6 to 816.2$)$ & $-71.0(0.05)$ \\
\hline \multicolumn{4}{|c|}{ Poverty by store locationt: } \\
\hline Low & $852.0(806.5$ to 897.4$)$ & 737.1 (695.7 to 778.5 ) & $-114.8(0.002)$ \\
\hline Moderate & 865.0 (830.1 to 899.9$)$ & 774.2 (732.9 to 815.4$)$ & $-90.8(<0.001)$ \\
\hline High & $870.0(838.2$ to 901.8$)$ & 761.4 (711.8 to 811.1$)$ & $-108.6(0.003)$ \\
\hline
\end{tabular}

${ }^{*} 1 \mathrm{kcal}=4.184$ kilojoules.

†Poverty is categorised by percentage of households in the store location or customer's residential zip code that were below twice the national poverty level: $<25 \%$ in low poverty neighbourhoods, $25 \%-45 \%$ in moderate poverty neighbourhoods, $>45 \%$ in high poverty neighbourhoods. 
Table 4| Results of linear regression analyses for mean energy content (kcal) of lunchtime fast food purchases in 2007 and 2009 , before and after introduction of calorie labelling

\begin{tabular}{|c|c|c|c|c|}
\hline & \multicolumn{2}{|c|}{ Model $1^{\star}$} & \multicolumn{2}{|c|}{ Model $2^{\star}$} \\
\hline & $\begin{array}{l}\text { Mean }(95 \% \mathrm{Cl} \text { ) energy } \\
\text { content/purchase (kcal) }\end{array}$ & $P$ value & $\begin{array}{l}\text { Mean }(95 \% \mathrm{Cl}) \text { energy } \\
\text { content/purchase (kcal) }\end{array}$ & $P$ value \\
\hline \multicolumn{5}{|l|}{ Estimated marginal means } \\
\hline 2007 & 829.3 (813.6 to 845.0 ) & - & 847.5 (837.2 to 857.8$)$ & - \\
\hline 2009 & 844.6 (831.6 to 857.6 ) & - & 827.3 (817.8 to 836.8 ) & - \\
\hline \multicolumn{5}{|l|}{ Parameter estimates } \\
\hline 2007 & Reference & - & Reference & - \\
\hline 2009 & $15.3(34.5$ to -3.8$)$ & 0.12 & $-20.2(-4.5$ to -35.9$)$ & 0.01 \\
\hline Sex (women-men) & $-111.4(-125.6$ to -97.2$)$ & $<0.001$ & $-52.5(-60.0$ to -45.0$)$ & $<0.001$ \\
\hline $\begin{array}{l}\text { Poverty level of store } \\
\text { locationt }\end{array}$ & $-6.3(-65.3$ to 52.8$)$ & $<0.001$ & 36.5 (0.3 to 72.7$)$ & 0.05 \\
\hline \multicolumn{5}{|l|}{ Description of purchase: } \\
\hline No of food items & - & - & 155.0 (139.6 to 170.3$)$ & $<0.001$ \\
\hline Beverage $(0=\mathrm{No} ; 1=\mathrm{Yes})$ & - & - & 33.7 (20.6 to 46.9$)$ & $<0.001$ \\
\hline Cost (inflation adjusted) & - & - & 104.8 (98.7 to 110.9$)$ & $<0.001$ \\
\hline
\end{tabular}

*Model 1 adjusted for restaurant chain, sex, and neighbourhood poverty. Model 2 further controlled for the number of food items purchased, beverage purchased, and cost. Both models included a variable for chain, to adjust for change in customer volume across the two years.

†Poverty is a continuous variable defined as the percentage of households in the store's zip code that were below twice the national poverty level. 
Table 5| Results of linear regression analyses for mean energy content (kcal) of lunchtime fast food purchases in 2009, by customers' use of information on calorie labelling

\begin{tabular}{|c|c|c|c|c|}
\hline & \multicolumn{2}{|c|}{ Model $1^{\star}$} & \multicolumn{2}{|c|}{ Model $2^{*}$} \\
\hline & $\begin{array}{l}\text { Mean }(95 \% \mathrm{Cl}) \text { energy } \\
\text { content/purchase (kcal) }\end{array}$ & $P$ value & $\begin{array}{l}\text { Mean }(95 \% \mathrm{Cl}) \text { energy } \\
\text { content/purchase (kcal) }\end{array}$ & $P$ value \\
\hline \multicolumn{5}{|l|}{ Estimated marginal means } \\
\hline Did not use information & 862.0 (849.0 to 875.2$)$ & - & 859.4 (851.8 to 867.0$)$ & - \\
\hline Used information & 765.9 (743.0 to 788.9$)$ & - & 781.6 (767.3 to 795.9 ) & - \\
\hline \multicolumn{5}{|l|}{ Parameter estimates } \\
\hline Did not use information & Reference & - & Reference & - \\
\hline Used information & $-96.2(-71.8$ to $-120,7)$ & $<0.001$ & $-77.8(-62.3$ to -93.4$)$ & $<0.001$ \\
\hline Sex (women-men) & $-95.2(-113.6$ to -76.7$)$ & $<0.001$ & $-46.9(-57.3$ to -36.5$)$ & 0.08 \\
\hline \multicolumn{5}{|l|}{ Age (years): } \\
\hline $18-24$ & 98.4 (63.3 to 133.5$)$ & \multirow[t]{4}{*}{$<0.001$} & 44.6 (27.9 to 61.3$)$ & \multirow[t]{4}{*}{$<0.001$} \\
\hline $25-34$ & 112.7 (89.5 to 125.9$)$ & & 27.0 (13.4 to 40.5$)$ & \\
\hline $35-44$ & 97.1 (71.6 to 122.6$)$ & & 26.5 (14.1 to 39.0$)$ & \\
\hline$\geq 45$ & Reference & & Reference & \\
\hline \multicolumn{5}{|l|}{ Poverty level†: } \\
\hline Of customer residence & $63.7(-13.3$ to 140.6$)$ & 0.10 & $40.1(6.2$ to 74.1$)$ & 0.02 \\
\hline Of store location & $10.4(-63.2$ to 84.1$)$ & 0.78 & $26.1(-16.3$ to 68.6$)$ & 0.23 \\
\hline \multicolumn{5}{|l|}{ Description of purchase: } \\
\hline No of food items & - & - & $148.6(130.9$ to 166.4$)$ & $<0.001$ \\
\hline Beverage $(0=\mathrm{No} ; 1=$ Yes $)$ & - & - & $25.2(8.7$ to 41.7$)$ & 0.003 \\
\hline Cost (inflation adjusted) & - & - & 102.8 (96.4 to 109.2$)$ & $<0.001$ \\
\hline
\end{tabular}

Models include city residents only (poverty level for customer residence could not be determined for non-city residents).

*Model 1 adjusted for restaurant chain, sex, and neighbourhood poverty. Model 2 further controlled for the number of food items purchased, beverage purchased, and cost. Both models included a variable for chain, to adjust for change in customer volume across the two years.

†Poverty is a continuous variable defined as the percentage of households in the store's zip code that were below twice the national poverty level. 